\title{
NILAI PENDIDIKAN KARAKTER DALAM PERTUNJUKAN WAYANG COKEK LAKON "NDARU ING BUMI SUKOWATI"
}

\author{
Ardian Yuliani Saputri \\ Program Pascasarjana, Universitas Sebelas Maret Surakarta \\ E-mail: ardianyees@gmail.com
}

\begin{abstract}
Abstrak
Tujuan penelitian ini adalah untuk mengungkap adanya nilai-nilai pendidikan karakter pertunjukan wayang Cokek pada lakon "Ndaru Ing Bumi Sukowati". Penelitian ini menggunakan metode penelitian kualitatif. Data dalam penelitian ini adalah rekaman pertunjukan wayang Cokek lakon "Ndaru Ing Bumi Sukowati" yang telah diselenggarakan pada 18 Juni 2017 di Alun-Alun Sasana Langen Putra Kabupaten Sragen. Sumber data dalam penelitian ini adalah percakapan antartokoh wayang dari rekaman video bersumber dari cerita asal-asul Kabupaten Sragen yang dibawakan oleh dalang Ki Joko Zendhen. Teknik pengumpulan data menggunakan observasi partisipan, studi dokumentasi, simak dan catat. Hasil dari penelitian menunjukkan adanya nilainilai pendidikan karakter yang terkandung di dalam pertunjukan wayang Cokek lakon "Ndaru Ing Bumi Sukowati" antara lain: jujur, disiplin, kerja keras, kreatif, mandiri, demokratif, rasa ingin tahu, semangat kebangsaan, cinta tanah air, mengahargai prestasi, bersahabat/komunikatif, cinta damai, gemar membaca, peduli lingkungan, peduli sosial, dan tanggung jawab. Berdasarkan temuan nilai-nilai pendidikan karakter yang terkandung di dalam wayang Cokek pada lakon tersebut, cerita ini dapat dijadikan sebuah model dalam membangun pendidikan karakter generasi bangsa baik dalam bidang akademik maupun nonakademik.
\end{abstract}

Kata Kunci: pendidikan karakter, wayang cokek, lakon.

\section{THE CHARACTER EDUCATION VALUES IN COKEK PUPPET SOW WITH THE PLAY OF “NDARU ING BUMI SUKOWATI”}

\begin{abstract}
The purpose of this research is to uncover the character education values of Cokekpuppet show in "Lakon Ndaru Ing Bumi Sukowati". This research uses qualitative research methods. The data in this study is a recording of the Cokek puppet show, "Lakon Ndaru Ing Bumi Sukowati" which was held on 18 June 2017 at Sasana Putra Square, Sragen. The data source in this study is a conversation excerpt between wayang characters from the recorded video in the original story of Asul Sragen Regency, hosted by Ki Joko Zendhen. The techniques used to collect data were participants ' observation, documentation, and notes. The data is collected by listening to and recording the speech in the Wayang Cokek performances of Ndaru Ing Bumi Sukowati. The results of this research include the values of the character education in the Cokek puppet show, Lakon Ndaru Ing Bumi Sukowati such as; honest, discipline, hard work, creative, self-reliant, democratize, curiosity, national spirit, love of homeland, award of achievement, friendly or communicative, love of peace, fond of reading, environmental care, social care, and responsibility. Based on the findings of the character education values contained in the Cokek puppet show in that play, this story can be used as a model to build the character education of our generations both in academic and non-academic fields.
\end{abstract}

Keywords: caharacter education, cokek puppet, play 


\section{PENDAHULUAN}

Wayang merupakan salah satu manifestasi budaya luhur bangsa Indonesia yang, bagi masyarakat Indonesia khususnya Jawa (Barat, Tengah, dan Timur) tidak terlepas dari pertunjukan wayang sebagai bagian dari kehidupannya. Pertunjukkan wayang yang hidup dan berkembang di Indonesia memiliki kontribusi bagi kehidupan masyarakat. Fungsi pertunjukkan wayang diantaranya sebagai hiburan, komunikasi, ungkapan jati diri, ritus keagamaan, pelestarian budaya, dan sarana pendidikan. Salah satu fungsi wayang sebagai sarana pendidikan dapat dimanfaatkan untuk pengajaran nilai-nilai karakter kepada peserta didik. Melalui pertunjukan wayang, krisis moral dan disorientasi budaya yang kini sedang melanda peradaban budaya bangsa Indonesia, secara perlahan akan dapat dieliminir menuju kearah sadar akan potensi budaya kelokalan yang bernilai luhur dan berdaya guna bagi generasi bangsa dan negara (Cahya, 2016: 118). Selain itu, pertunjukan wayang memilki kualitas seni yang tinggi sehingga perlu dilestarikan dan dikembangkan agar bermanfaat bagi kehidupan bangsa dan bernegara. Oleh karena itu, tidak mengherankan ketika tahun 2003 UNESCO sebagai salah satu badan dunia menobatkan wayang Indonesia sebagai Masterpiece of the Oral andIntangible Heritage of Humanity, wayang sebagai karya agung dunia.

Pertunjukan wayang Cokek yang hidup dan berkembang di kabupaten Sragen, dipandang sebagai salah satu bentuk tontonan rakyat yeng syarat dengan nilai-nilai kerakyatannya. Sebagai sebuah tontonan, pertunjukan wayang Cokek sering dipentaskan dalam sebuah hajatan yang penontonnya terdiri atas berbagai lapisan masyarakat. Disamping sebagai tontonan, pertunjukan wayang juga sebagai tuntunan. Melalui lakon dalam cerita yang disajikan dapat memberikan ajaran moral dan nilai-nilai yang bermanfaat dalam kehidupan. Setiap lakon dalam cerita pewayangan selalu mengarah kepada sebuah tema yang berkaitan erat dengan fenomena dan realitas kehidupan. Seperti halnya tema kepahlawanan, kepemimpinan, kesetiaan, dan sebagainya.
Tema-tema tersebut akan tersajikan dengan muatan nilai-nilai kehidupan yang dapat dijadikan sebagai bekal tuntutan bagi penonton setelah menyaksikan pertunjukan wayang. Selain itu, pertunjukan wayang adalah sebagai tatanan nilai-nilai keindahan yang bersentuhan dengan rasa estetik (keindahan) yang dirasakan langsung oleh penonton. Berkenaan dengan rasa penikmatan sebagai bentuk respon estetik antara pertunjukan wayang dan penontonnya, kesemuanya dapat tersaji secara audio-visual.

Wayang Cokek dimainkan dalang Ki Joko Zenden dari Ngrampal dengan waranggana Nyi Ninik dari Pilangsari. Pagelaran Wayang kreatif Cokek ini menjadi tontonan menarik karena berkolaborasi dengan Ketoprak Serambi Sukowati. Wayang Cokek bercerita tentang sejarah Kabupaten Sragen. Hari Jadi Kabupaten Sragen ditetapkan dengan Perda Nomor 4 Tahun 1987, yaitu pada hari Selasa Pon, tanggal 27 Mei 1746. Tangal dan waktu tersebut adalah dari hasil penelitian serta kajian pada fakta sejarah, ketika Pangeran Mangkubumi yang kemudian hari menjadi Sri Sultan Hamengku Buwono ke-1, menancapkan tonggak pertama melakukan perlawanan terhadap Belanda menuju bangsa yang berdaulat dengan membentuk suatu pemerintahan lokal di Desa Pandak Karangnongko masuk tlatah Sukowati.

Wayang Cokek mungkin hanya dikenal di Kabupaten Sragen yang dijuluki sebagai tlatah Sukowati. Wayang yang ditampilkan menggambarkan karakter tokoh-tokoh dalam lakon dengan wujud yang lucu. Begitu juga gamelan yang ditabuh para niyaga grup karawitan selalu menyuguhkan gendhing-gendhing Cokek gaya Sragenan. Lakon "Ndaru Ing Bumi Sukowati" bercerita tentang perjuangan Pangeran Mangkubumi melawan penjajah Belanda hingga mendirikan Pemerintahan di Sragen. Ditengah beratnya perjuangan muncul tokoh Patih Pringgalaya yang berkhianat dengan cara licik menjadi antek Belanda. Bersyukur, Pangeran Mangkubumi cukup waspada sehingga berbagai persoalan bisa diatasi. Meski mengangkat kisah sejarah yang terjadi ratusan tahun lalu, namun Dalang 
Wayang Cokek dan Grup Ketoprak Serambi Sukowati pimpinan Mbah Pine Wiyatno ini berhasil meramu dengan realitas Sragen masa kini. Jadilah tontonan yang menyegarkan.

Menurut Suharyono (2005:25) wayang berasal dari kata wewayangan atau wayangan yang berarti bayangan. Pertunjukan bayangan kemudian berubah menjadi petunjuk ritual memuja nenek moyang, semakin lama pemikiran manusia semakin berkembang dan pertunjukan bayang-bayang menjadi seni pertunjukan. Fungsi pertunjukan wayang adalah untuk penghayatan estetis, hiburan, komunikasi, ungkapan jati diri, berkait dengan norma sosial, pengesahan lembaga sosial dan ritus keagamaan, sarana pendidikan, pengintegrasian masyarakat, kesinambungan kebudayaan, dan sebagai lambang yang penuh makna (Sarwanto, 2007:300-356). Menurut Santoso (2011: 39) dalam konteks kebudayaan, tujuan utama pertunjukan wayang yaitu memberikan petunjuk kepada manusia untuk berlaku baik dan benar serta memacu cipta, rasa, dan karsa ikut membangun masyarakat luas.

Dalam pertunjukan wayang terdapat kearifan lokal yang bermanfaat untuk membangun karakter dan jati diri bangsa Indonesia yang tergambarkan melalui watak tokoh wayang. Seni wayang terdapat kearifan lokal yang bermanfaat untuk membangun karakter dan jatidiri bangsa Indonesia yang tergambarkan melalui watak tokoh dalam wayang. Menurut Mubah (2011:305), Jati diri bangsa sebagai nilai identitas masyarakat harus dibangun secara kokoh dandiinternalisasikan secara mendalam. Caranya, dengan menanamkan nilai-nilai kearifan lokal sejak dini kepada generasi muda.

Pendidikan karakter (Narwanti, 2011: 14) adalah suatu sistem penanaman nilai-nilai karakter kepada warga sekolah yang meliputi komponen pengetahuan, kesadaran, atau kemauan, dan tindakan untuk melaksanakan niali-nilai tersebut, baik terhadap Tuhan YME, diri sendiri, sesama, lingkungan, maupun kebangsaan sehingga menjadi manusia insan kamil. Dalam merubah keadaan dan derajat suatu masyarakatadalahmelaluipengembangan karakter menjadi lebih baik (Megawangi, 2004: 2). Selain itu, Retnowati, Mardapi, \& Prihadi (2017: 230) menambahkan bahwa pendidikan karakter dapat dijadikan sebagai investasi nilai kultural guna membangun watak, moralitas, dan kepribadian masyarakat yang dilakukan dalam waktu panjang, kontinyu, intens, konstan, dan konsisten.

Kementerian Pendidikan Nasional telah merumuskan 18 pilar nilai-nilai karakter yang mana didalamnya memuat nilai-nilai luhur yang mencakup hubungan manusia sebagai makhluk individu, sosial, beragama, dan religius. Adapun 18 nilai pendidikan karakter menurut Pusat Kurikulum Kementerian Pendidikan Nasional (2010: 9 - 10) sebagai berikut ini. 1) Religius, sikap dan perilaku yang patuh dalam melaksanakan ajaran agama yang dianutnya, toleren terhadap pelaksanaan peribadatan agama lain dan membangun kerukunan antar umat beragama; 2) Jujur, perilaku yang didasarkan pada upaya mejadikan dirinya sebagai orang yang selalu dapat dipercaya dalam pikiran, perkataan, dan perbuatan. 3) Toleransi, sikap dan tindakan yang menghargai perbedaan agama, suku, etnis, pendapat, sikap, dan tindakan orang lain yang berbeda dari dirinya. 4) Disiplin, tindakan yang menunjukan perilaku tertib dan patuh pada berbagai ketentuan dan peraturan. 5) Kerja keras, perilaku yang menunjukan upaya sungguhsungguh dalam mengatasi berbagai hambatan belajar dan tugas, serta menyelesaikan tugas dengan sebaik-baiknya. 6) Kreatif, berpikir dan melakukan sesuatu untuk menghasilkan cara atau hasil baru dari sesuatu yang telah dimiliki. 7) Mandiri, sikap dan perilaku yang tidak mudah tergantung pada orang lain dalam menyelesaikan tugas. 8) Demokratis, cara berpikir, bersikap, bertindak yang menilai sama hak dan kewajiban dirinya dan orang lain. 9) Rasa ingin tahu, sikap dan tindakan yang selalu berupaya untuk mengetahui lebih mendalam dan meluas dari sesuatu yang dipelajarinya, dilihat, dan didengar. 10) Semangat kebangsaan, cara berpikir, bertindak, dan berwawasan yang menempatkan kepentingan bangsa dan negara 
di atas kepentingan diri dan kelompoknya. 11) Cinta tanah air, cara berpikir, bersikap, dan berbuatyangmenunjukankesetiaan, kepedulian, dan penghargaan yang tinggi terhadap bahasa, lingkungan fisik, sosial, budaya, ekonomi, dan politik bangsa. 12) Menghargai prestasi, sikap dan tindakan yang mendorong dirinya untuk menghasilkan sesuatu yang berguna bagi masyarakat, dan mengakui, serta menghormati keberhasilan orang lain. 13) Bersahabat/ komunikatif, tindakan yang memperlihatkan rasa senang berbicara, bergaul, dan bekerja sama dengan orang lain. 14) Cinta damai, sikap, perkataan, dan tindakan yang menyebabkan orang lain merasa senang dan aman atas kehadiran dirinya. 15) Gemar membaca, kebiasaan menyediakan waktu untuk membaca berbagai bacaan yang memberikan kebajikan bagi dirinya. 16) Peduli lingkungan, sikap dan tindakan yang selalu berupaya mencegah kerusakan pada lingkungan alam disekitarmya dan mengembangkan upaya-upaya untuk memperbaiki kerusakan alam yang sudah terjadi. 17) Peduli sosial, sikap dan tindakan yang selalu ingin memberi bantuan pada orang lain dan masyarakat yang membutuhkan. 18) Tanggungjawab, sikap dan perilaku seseorang untuk melaksanakan tugas dan kewajibannya, yang seharusnya dia lakukan terhadap diri sendiri, masyarakat, lingkungan (alam, sosial, dan budaya), negara dan Tuhan Yang Maha Esa.

Dua penelitian yang sama terkait pembahasan wayang adalah penelitian yang telah dilakukan Budiasa pada tahun 2014 berjudul "Memahami Nilai-Nilai Budaya Tradisi dalam Lakon Seni Pertunjukan Bali: sebagai Wahana Pendidikan Karakter Bangsa". Dalam penelitian tersebut, pertunjukan wayang yang diteliti merupakan wayang Bali yang mengangkat beberapa lakon. Sementaraitu, penelitian lain adalah penelitian terhadap wayang Cokek khas kabupaten Sragen yang mengangkat satu lakon yaitu "Ndaru Ing Bumi Sukowati". Penelitian yang telah dilakukan Herawati (2015) berjudul "Nilai-nilai Karakter yang Terkandung dalam Dolanan Anak se-DIY 2013" juga mengangkat nilai-nilai karakter dalam kajiannya. Akan tetapi, penelitian yang dilakukan Herawati dolanan anak sebagai subjek kajiannya sedangkan peneliti mengangkat pertunjukan wayang. Tulisan ini bertujuan untuk mengungkap adanya nilai-nilai pendidikan karakter pada wacana pertunjukan wayang Cokek pada lakon Ndaru Ing Bumi Sukowati.

\section{METODE}

Metode penelitian yang digunakan dalam penelitian ini adalah kualitatif. Sugiyono (2005:1) sering menyebut metode penelitian kualitatifsebagai metode penelitian naturalistik karena penelitiannya dilakukan pada kondisi yang alamiah (natural setting). Penelitian ini difokuskan pada satu lakon yaitu "Ndaru Ing Bumi Sukowati" dengan mengamati pertunjukannya melalaui rekaman video. Data dalam penelitian ini adalah rekaman video pertunjukan wayang Cokek lakon "Ndaru Ing Bumi Sukowati" yang telah diselenggarakan pada 18 Juni 2017 di Alun-Alun Sasana Langen Putra Kabupaten Sragen.Objek penelitian ini adalah pendidikan karakter. Subjek penelitiannya adalah pertunjukan wayang Cokek lakon "Ndaru Ing Bumi Sukowati". Sumber data dalam penelitian ini adalah percakapan antartokoh wayang bersumber dari cerita asal-asul Kabupaten Sragen yang dibawakan oleh dalang $\mathrm{Ki}$ Joko Zendhen. Teknik yang digunakan untuk mengumpulkan data adalah observasi partisipan, dokumentasi, dan catat.Data dikumpulkan dengan cara menyimak dan mencatat tuturan percakapan yang ada dalam pergelaran wayang Cokek lakon "Ndaru Ing Bumi Sukowati". Hasil dari penelitian ini akan dipaparkan dalam uraian deskriptif argumentatif. Keabsahan data menggunakan triangulasi sumber data dan teknik atau metode. Prosedur analisis data meliputi pengumpulan data, reduksi data, penyajian data, dan penarikan kesimpulan/ verifikasi. 


\section{HASIL DAN PEMBAHASAN Sinopsis Wayang Cokek Lakon Ndaru Ing Bumi Sukowati}

Lakon "Ndaru Ing Bumi Sukowati" bercerita tentang perjuangan Pangeran Mangkubumi melawan penjajah Belanda hingga mendirikan pemerintahan di Sragen. Ditengah beratnya perjuangan muncul tokoh Patih Pringgalaya yang berkhianat dengan cara licik menjadi antek Belanda. Bersyukur, Pangeran Mangkubumi cukup waspada sehingga berbagai persoalan bisa diatasi. Pangeran Mangkubumi adik dari Sunan Paku Buwono II di Mataram sangat membenci Kolonialis Belanda. Apalagi setelah Belanda banyak mengintervensi Mataram sebagai Pemerintah yang berdaulat. Oleh karena itu, dengan tekad yang menyala bangsawam tersebut lolos dari istana dan menyatakan perang dengan Belanda.

Atas sikap adiknya tersebut Sunan PB II tidak tega kepada adiknya, tapi karena sudah berhutang budi kepada kompeni, beliau memberi bekal berupa tombak pusaka keraton "Kanjeng Kyai Pleret" dan uang secukupnya. Dalam sejarah peperangan tersebut disebut perang Mangkubumen (1746 - 1757). Dalam perjalanan perangnya Pangeran Mangubumi dengan pasukannya sampailah ke desa Pandak Karangnongko masuk tlatah Sukowati. Di desa ini Pangeran Mangkubumi membentuk Pemerintahan Pemberontak Desa Pandak Karangnongko dijadikan pusat pemerintahan Praja Sukowati dan beliau meresmikan namanya menjadi Pangeran Sukowati serta mengangkat pula beberapa pejabat pemerintahan.

Secara geografis, desa Pandak Karangnongko terletak di tepi jalan lintas tentara kompeni Surakarta - Madiun. Pusat pemerintahan tersebut dianggap kurang aman, kemudian dipindah ke Desa Gebang yang terletak disebelah tenggara Desa Pandak Karangnongko. Sejak itu Pangeran Sukowati memperluas daerah kekuasaannya serta memperkuatpasukannyadenganbahumembahu bersama saudaranya Raden Mas Said dan Adipati dari Grobogan yaitu KRT Martopuro dan beberapa kerabat yang bersimpati dengan perjuangan Pangeran Mangkubumi.
Pusat Pemerintahan Praja Sukowati yang ada di Desa Gebang ini pun akhirnya diketahui olehkompeniBelandayangbekerjasamadengan kasunanan dan akan mengadakan penyerangan ke desa Gebang. Pasukan gabungan antara kompeni dan pasukan dari Keraton Surakarta tersebut dipimpin oleh Patih Pringgalaya (Patih dari PB II). Untung rencana tersebut diketahui oleh Petugas Sandi (Intetegent) dan Pangeran Sukowati. Dengan berbagai pertimbangan maka Pusat Pemerintahan akan dipindahkan ke Desa Jekawal.

Dalam proses boyongan dari Gebang ke Jekawal (Tangen) melewati suatu Padepokan yang dipimpin oleh seorang kyai, yakni Kyai Srenggi. Konon Kyai Srenggi ini adalah salah seorang panglima perang dari Sunan Amangkurat di Kartosura, yang sebetulnya bernama asli Tumenggung Alap-Alap. Untuk menghilangkan jejak beliau berganti nama Kyai Srenggi.

Pada saat Pangeran Sukowati singgah di padepokan tersebut oleh Kyai Srenggi disuguhi legen dan palawija. Pangeran Sukowati merasa sangat puas dan beliau bersabda bahwa tempat tersebut diberi nama "Sragen" dari kata "Pasarah Legen" dan Kyai Srenggi diberi sebutan Ki Ageng Srenggi. Setelah pusat Pemerintahan berada di Jekawal maka Raden Mas Said diambil menantu oleh Pangeran Mangkubumi/Pangeran Sukowati dinikahkan dengan putrinya bernama BRA Suminten. Perlawanan pasukan Pangeran Sukowati semakin kuat dan karena kompeni merasa terdesak kemudian membuat siasat memecah belah dengan mengadakan Perjanjian Pelihan Negeri atau terkenal dengan Perjanjian Giyanti Tahun 1755 dimana Kerajaan Mataram dipecah menjadi Kasunanan Surakarta dan Kasultanan Yogyakarta dengan mengangkat Pangeran Mangkubumi/Pangeran Sukowati menjadi Sultan Hamengku Buwono I.

\section{Nilai Pendidikan Karakter dalam Wayang Cokek Lakon "Ndaru Ing Bumi Sukowati"}

Pertunjukkan Wayang Cokek dalam penelitian ini berlangsung pada pada 18 Juni 2017 yang bertempat di di Alun-Alun Sasana 
Langen Putra Kabupaten Sragen. Dalam pertunjukannya wayang Cokek berkolaborasi dengan ketoprak. Pertunjukan Wayang Cokek mengangkat lakon Ndaru Ing Bumi Sukowati. Cerita yang diangkat dalam lakon tersebut mengungkap sejarah kabupaten Sragen. Wayang Cokek merupakan sebuah inovasi baru, yaitu Wayang Cokek Sragen yang sudah beberapa kali pentas hingga ke Taman Mini Indonesi Indah (TMII) Jakarta, launching di rumah pendapa rumah dinas bupati pada tahun 2013. Wayang Cokek ini bercerita tentang sejarah Pangeran Mangkubumi yang berpetualang melawan kompeni Belanda hingga menjadi raja pertama. Upaya agar peserta didik dapat mengenali nilai moral tidak hanya melalui sebuah penjelasan atau bahan bacaan, tetapi dapat juga berpartisipasi dengan cara berperan aktif merasakan secara fisikal atau empatinya (Nugraheni, 2018: 164 - 165). Begitu pula dengan nilai pendidikan karakter. Melalui berpartisipasi dan berperan aktif untuk terlibat di dalam pertunjukan wayang Cokek seperti menyaksikan pertunjukannya, maka diharapkan nilai-nilai pendidikan karakter dapat dikenali dan ditanamkan.

Adapun nilai-nilai pendidikan karakter yang terkandung di dalam pertunjukan wayang Cokek lakon "Ndaru Ing Bumi Sukowati"yaitu sebagai berikut.

1. Jujur

Nilai jujur merupakan perilaku yang didasarkan pada upaya menjadikan dirinya sebagai orang yang selalu dapat dipercaya dalam perkataan, tindakan, dan pekerjaan dalam hidup bermasyarakat. Pelukisan nilai jujur dapat terlihat pada kutipan percakapan Pangeran Mangkubumi kepada Joyosentono, yaitu sebagai berikut.

"Aku antuk dhawuhe Ki Ageng Srengging ana ndaru cumlorot ing bumi Sukowati pernahe ana sisih etan ana sabranging bengawan ana tengahe ngalas jati. Mula ayo bebadra goleki papan kang dupadi mbok menawa bisa kinarya sowan nggonku nggayuh dhuwur memayu hayuningrat memayu hayuning bawana."
“Aku mendapat perintah Ki Ageng Srengging ada wahyu mengarah di Bumi Sukowatitepatnyadisebelahtimurseberang sungai di tengah hutan jati. Maka, ayo berjuang mencari tempat yang tepat yang mungkin bisa tercapai keinginanku untuk menggapai tinggi menjaga kesejahteraan diri menjaga kesejahteraan dunia."

Pada kutipan di atas, terdapat pelukisan nilai jujur oleh Pangeran Mangkubumi yang mengakui bahwa dirinya mendapat perintah dari Ki Ageng Srenggi tentang tempat yang bisa dijadikan sebagai markas untuk menjaga kesejahteraan dunia. Oleh karena itu, untuk membuktikan perkataannya, Pangeran Mangkubumi mengajak Joyosentono mencari tempat tersebut.

2. Disiplin

Nilai disiplin adalah nilai yang menekankan pada tindakan seseorang untuk taat, tertib, dan patuh pada berbagai ketentuan dan peraturan. Pelukisan budaya disiplin tersirat dalam kutipan percakapan sebagai berikut.

"Aku mung menehi ngerti yen ta sira sakarone, negara iki ana tatanane mangka tata praja jumbuh lawan apa kang dadi dhawuhku."

"Aku hanya memberi tahu kalau kalian berdua, negara ini ada peraturannya sehingga peraturan raja cocok dengan apa yang menjadi perintahku."

Berdasarkan kutipan percakapan di atas, terdapat pelukisan nilai disiplin oleh Raden Mas Said yang disiplin dalam menegakan peraturan yang berlaku di negaranya. Raden Mas Said menegur dua orang yang ingin berbuat kejahatan di Bumi Sukowati dan mengajaknya untuk mematuhi peraturanperaturan yang ada.

3. Kerja keras

Nilai kerja keras merupakan perilaku yang menunjukan upaya sungguh-sungguh 
dalam mengatasi berbagai hambatan belajar dan tugas, serta menyelesaikan tugas dengan sebaik-baiknya. Nilai kerja keras dapat dilukiskan pada kutipan percakapan tersebut.

"Wat-watana perilakune Pangeran Mangkubumi. Ora wurung kae mengko bakal nyusun kakuwatan, trahe ngaluhur mijining andhan apa-apa tunasing andhana warih. Kae priyagung luhur sing ora kena koanggep sepele. Ora wurung ake mengko mudun nang Bumi Sukowati beteng kandel jagad njero mesthi golek ringkihe kompeni."

"Awas-awasilah perilakunya Pangeran Mangkubumi. Tidak lain dia nanti akan menyusun kekuatan, orangnya luhur benih tumpuan apapun tunasnya tumpuan air. Dia lelaki agung luhur yang tidak dapat dianggap sepele. Tidak lain nanti sampai di Bumi Sukowati pagar tebal dunia di dalamnya pasti mencari kelemahan kompeni."

Berdasarkan kutipan percakapan yang dilakukanPatihPringgoloyodiatas, terdapat pelukisan nilai kerja keras yang dilakukan olehPangeran Mangkubumi.Dalamkutipan di atas diceritakan bahwa Pringgoloyo memerintahkan seseorang untuk mematamatai Pangeran Mangkubumi. Pangeran Mangkubumi dikenal sebagai orang yang tidak bisa diremehkan, beliau akan berusaha dan bersungguh-sungguh dalam mecari kelemahan kompeni sehingga bisa mengusir kompeni dari wilayahnya.

\section{Kreatif}

Nilai kreatif yaitu berpikir dan melakukan sesuatu untuk menghasilkan cara atau hasil baru dari sesuatu yang telah dimiliki. Kreatif adalah mampu menyelesaikan masalah secara movatif, luwes, kreatif, berani mengambil keputusan dengan cepat dan tepat, memiliki ide baru. Pengertian tersebut sejalan dengan Noviyanti \& Sutiyono (2017: 110) bahwa kreatif adalah kemampuan dalam memberikan gagasan baru. Pelukisan nilai kreatif dapat dilihat pada kutipan percakapan di bawah ini.

"Aku antuk dhawuhe Ki Ageng Srengging ana ndaru cumlorot ing Bumi Sukowati pernahe ana sisih etan ana sabranging bengawan ana tengahe ngalas jati. Mula, ayo bebadra goleki papan kang dupadi mbok menawa bisa kinarya sowan nggonku nggayuh dhuwur memayu hayuningrat memayu hayuning bawana."

"Aku mendapat perintah Ki Ageng Srengging ada wahyu mengarah di Bumi Sukowatitepatnyadisebelahtimurseberang sungai di tengah hutan jati. Maka, ayo berjuang mencari tempat yang tepat yang mungkin bisa tercapai keinginanku untuk menggapai tinggi menjaga kesejahteraan diri menjaga kesejahteraan dunia."

Berdasarkan kutipan di atas, Pangeran Mangkubumi mendapat petunjuk dari Ki Ageng Srengging. Setelah mendapat petunjuk tersebut, beliau berusaha mencari tempat yang dimaksud dan akan menjadikan hutan jati yang dimaksud tersebut menjadi sebuah tempat yang dapat membantu tercapainya cita-citanya dalan menjaga kesejahteraan dunia.

\section{Demokratis}

Demokratis adalah cara berpikir, bersikap, dan bertindak yang menilai sama hak dan kewajiban dirinya dan orang lain. Sikap semacam ini akan mendorong peserta didik mengutarakan pendapat dengan sopan karena memperhatikan hak dan kewajiban orang lain disekitarnya. Nilai demokratis dapat dilihat pada kutipan percakapan di bawah ini.

"Mula saka kuwi, sakdurunge si abdi jejodohan lawan atmajaku putri si inten kinarya bebungah anggonku bebela nyirnakake angkaraning jagad wujude begal kang ana ing alas jati lor ing bengawan kene, luwih becik yen ta si abdi mrepegi kahanane inten atmajaku.Mara gage yayi tamatna kanthi premati supaya bebungah saka pun kakang iki mengko ora manjing dadi kasusahan." 
"Oleh karena itu, sebelum si abdi dijodohkan dengan anakku putri si inten yang menjadikan berbahagia untukku berjuang menyirnakan kejahatan dunia berwujud begal yang ada di hutan jati utara di sungai sini, lebih baik kalau si abdi melihat keadaan inten anakku. Datanglah cepat perhatikan dengan cermat supaya bahagia, karena ini kakak nanti tidak berakhir menjadi kekecewaan."

Berdasarkan kutipan percakapan di atas, menunjukkan bahwa Pangeran Mangkubumi bersikap demokratis terhadap Mas Said. Dikarenakan rasa terimakasih dan bahagianya Pangeran Mangkubumi terhadap Mas Said yang telah berhasil menyirnakan kejahatan berupa begal maka dijodohkan dengan anaknya. Sebelum perjodohan, Mas Said diberikan haknya dan kewajibannya melihat dan menilai anaknya terlebih dahulu supaya tidak kecewa nantinya.

6. Rasa ingin tahu

Rasa ingin tahu yaitu sikap dan tindakan yang selalu berupaya untuk mengetahui lebih mendalam dan meluas dari sesuatu yang dipelajarinya, dilihat, dan didengar. Pendidikan sebagai pranata sosial, baik formal dan informal sebaiknya dapat menjadi dasar dalam proses mendidik dengan nilai-nilai budaya, sistem kepercayaan dan pengetahun (Salu, 2017: 70). Oleh karena itu, melalui rasa ingin tahu dapat digunakan sebagai dasar proses mendidik sehingga peserta didik dapat memiliki pengetahuan yang luas.

Nilai rasa ingin tahu ditunjukan pada kutipan percakapan antara kompeni Van Der Hook dan pribumi Jaya Hadi Winata berikut ini.

Jaya Hadi Winata :'Londo iku apa ya mangan beras?"

Van Der Hook: "Beras and ora doyan." Jaya Hadi Winata: "Nek gedhang?" Van Der Hook :"And gedhang doyan" Jaya Hadi Winata :"Roti?"
Van Der Hook :"Roti and doyan." Jaya Hadi Winata :"Bule itu apa iya makan beras?"

Van Der Hook: "Beras dan tidak doyan." Jaya Hadi Winata : "Kalau pisang?"

Van Der Hook : "Dan pisang doyan." Jaya Hadi Winata : "Roti?"

Van Der Hook : "Roti dan doyan."

Berdasarkan kutipan di atas, Jaya Hadi Winata memiliki rasa ingin tahunya terhadap makanan yang biasa dimakan orang luar negeri. Oleh karena itu, dia banyak bertanya langsung kepada Van Der Hook sebagai orang luar negeri agar terpenuhi dan terjawab rasa ingin tahunya itu.

7. Semangat kebangsaan

Semangat kebangsaan merupakan cara berpikir, bertindak, dan berwawasan yang menempatkan kepentingan bangsa dan negara diatas kepentingan diri dan kelompoknya. Dalam hal ini peserta didik akan menyadari mengutamakan kepentingan umum adalah penting dan setelahnya menempatkan kepentingan pribadinya. Pelukisan semangat kebangsaan ditunjukkan dalam percakapan Jaya Sentana berikut ini.

"Iki rekasa tenan, ora ger wong gelem nglakoni, mangka bobol bolote umpama konangan kompeni, ora mung bandha donya totoane nanging nyawa dadi taruhane."

"Ini susah beneran, tidak setiap ora mau melakukan, sehingga dapat celaka seandainya ketahuan kompeni. Tidak hanya harta dunia taruhannya tetapi nyawa yang menjadi taruhannya."

Berdasarkan kutipan percakapan Jayasentana di atas menunjukkan adanya nilai semangat kebangsaan. Pada percakapan tersebut demi kepentingan bangsa dan negaranya ia rela harta dunia bahkan nyawanya menjadi taruhannya. Hal tersebut merupakan cara berpikir dan 
bertindak yang menempatkan kepentingan bangsa dan negara diatas kepentingan pribadinya.

8. Cinta tanah air

Cinta tanah air merupakan cara berpikir, bersikap, dan berbuat yang menunjukan kesetiaan, kepedulian, dan penghargaan yang tinggi terhadap bahasa, lingkungan fisik, sosial, budaya, ekonomi, dan politik bangsa. Nilai cinta tanah air dilukiskan oleh Ki Ageng Srengging yang terdapat pada kutipan dialog Pangeran Mangkubumi berikut ini.

"Malah saka cuwane marang bangsa kompeni panjenengane uga bakal sabyantu nglawan lekasku ngunggulake gula kelapa nulad penjajah saka Bumi Sukowati."

"Karena dari kecewanya kepada bangsa kompeni beliau juga akan membantu melawan seperti keinginanku menyatakan perang kepada penjajah dari Bumi Sukowati."

Berdasarkan kutipan dialog di atas menunjukkan nilai cinta tanah air yang dilakukan oleh Ki Ageng Srengging. Kutipan Pangeran Mangkubumi tersebut menceritakanbahwakarenarasakecewanya kepada kompeni, Ki Ageng Srengging akan membantu melawan penjajah dan mengusirnya dari Bumi Sukowati.

\section{Menghargai prestasi}

Menghargai prestasi merupakan sikap dan tindakan yang mendorong dirinya untuk menghasilkan sesuatu yang berguna bagi masyarakat, dan mengakui, serta menghormati keberhasilan orang lain. Nilai menghargai prestasi ditunjukkan pada kutipan percakapan Pangeran Mangkubumi berikut ini.

"Gedhe rasaning atiku, dene si abdigolong gilig sabyantu marang pun kakang melu bebadra ana Bumi Sukowati kene kanggo jejegake pranataning abdi tumindak adil marang bebener bela marang kawula kang katemah dening panguwasa praja kang hambegsiya lan nista lila legawa ngorbanake negara kanggo kepentingan bangsa manca tinindahan dening patih kang tega marang kawula negara yaiku si Patih Pringgoloyo. Saka bungah lan gambiraning atiku pun kakang bakal jodhohake si abdi lawan anakku si inten." "Besar rasanya hatiku, sedangkan si abdi bertekad bulat membantu kakak ikut berjuang di Bumi Sukowati sini untuk meluruskan peraturan abdi bertindak adil kepada kebenaran membela masyarakat yang dijajah penguasa raja yang kejam dan nista rela mengorbankan negara untuk kepentingan bangsa manca ditumpangi oleh patih yang tega kepada rakyat negara yaiku Si Patih Pringgoloyo. Dari bahagia dan senangnya hatiku kaka akan menjodohkan Si Abdi kepada anakku Si Inten.”

Berdasarkan kutipan di atas, terdapat nilai menghargai prestasi. Atas prestasinya Raden Mas Said yang telah bertekad membantu berjuang di Bumi Sukowati melawan penjajah dan telah berbuat adil serta menegakkan kebenaran maka Pangeran Mangkubumi memberikan hadiah perjodohan kepadanya.

\section{Bersahabat/komunikatif}

Nilai persahabatan diperlihatkan dalam sebuah kutipan percakapan atau wacana yang menuntun orang berbicara, bergaul, dan bekerja sama dengan orang lain dengan baik. Sikap ini akan membantu peserta didik dalam kemampuan bersosial. Dengan demikian akan terjalin hubungan baik antara peserta didik dan lingkungan belajar. Pelukisan nilai persahabatan dapat ditunjukan pada kutipan Pangeran Mangkubumi sebagai berikut.

"Ngaturaken agunging panuwun dening yayi Mas Said kang sabyantu marang pun kakang. Aja sinengga pun kakang tan uninga marang kahanane si abdi."

"Mengucapkan terima kasih sebesarbesarnya dek Mas Said yang membantu kakak. Jangan dikira kakak tidak mengetahui dengan keadaan si abdi." 
Secara implisit dan eksplisit makna yang tercermin dari wacana di atas mengharapkan agar kita menjaga keharmonisan dengan lingkungan dan saudara sendiri, baik dalam perkataan maupun tingkah laku, agar hidup rukun dan damai terjaga serta mewariskan budaya santun kepada semua orang sehingga kelak menemukan bahagia. Berdasarkan kutipan di atas, Pangeran Mangkubumi berterimakasih kepada Mas Said karena telah dibantu dan mau bekerja sama dengan baik dalam mengusir penjajah.

11. Cinta damai

Pelukisan nilai cinta damai yang menekankan pada sikap, perkataan, dan tindakan yang menyebabkan orang lain merasa senang dan aman atas kehadirannya. Nilai tersebut terlihat dalam wacana berikut.

"Aku mung menehi ngerti yen ta sira sakarone, negara iki ana tatanane mangka tata praja jumbuh lawan apa kang dadi dhawuhku. Mula saka kuwi aja ganggu lan ngridu katentramane para kawula sa-Bumi Sukowati."

"Aku hanya memberi tahu kalau kalian berdua, negara ini ada peraturannya sehingga peraturan raja cocok dengan apa yang menjadi perintahku. Oleh karena itu jangan mengaggu dan merusak ketentraman masyarakat se-Bumi Sukowati."

Pada kutipan percakapan tersebut, terlukiskan nilai cinta damai yang ditunjukkan oleh Mas Said. Kecintaannya Mas Said terhadap Bumi Sukowati menjadikan dirinya merasa perlu menjaga kententraman masyarakat dan lingkungannya. Oleh karena itu, Mas Said akan berusaha melarang siapapun yang akan merusak kedamaian di Bumi Sukowati.

12. Gemar membaca

Membaca merupakan modal awal dalam mengembangkan wawasan mengenau hal apapun, membaca mampu membuka cakrawala pengetahuan. Tentunya hal ini sangat bermanfaat. Ungkapan-ungkapan yang dilontarkan para tokoh dalam pertunjukan wayang tidak semata-mata hanya untuk menghibur penonton, tetapi dibalik dialog tersirat makna tuntunan kepada masyarakat untuk aktif dan giat menuntut ilmu sehingga masyarakat menjadi cerdas. Makna cerdas di sini adalah memiliki kemampuan dibidang ilmu sehingga tidak ketinggalan zaman yang dilandaskan pada etika dan moral. Dalam konsep nyata, masyarakat memiliki kecerdasan yang didukung oleh moral dan etika yang baik yang dapat dipelajari melalui sebuah tembang yang kaya akan nilai-nilai kehidupan.

"Mangka tembange sinom wis nyarate nuladha laku utama tumrape wong tanah Jawi, wong agung ing ngeksi ganda, panembahan senapati, kepati hamarsudi, sudaning hawa nepsu, pinepsu tapa brata."

"Sehingga tembangnya sinom sudah menyiratkan contoh perilaku utama di tanah Jawa, orang agung di Mataram, panembahan senapati, menjadi contoh, mengurangi hawa nafsu, dengan melakukan puasa."

Pada kutipan dialog di atas, ditunjukkan nilai gemar membaca oleh Pangeran Mangkubumi. Pangeran Mangkubumi menyebutkan makna dan perilaku utama yang pantas dijadikan panutan di Tanah Jawa terdapat dalam tembang Sinom. Hal tersebut menyiratkan bahwa Pangeran Mangkubumi ialah orang yang gemar membaca sehingga memiliki wawasan yang luas, apabila tidak membaca ia tidak akan tahu makna-makna yang terdapat dalam tembang.

13. Peduli lingkungan

Nilai peduli lingkungan dapat ditunjukkan melalui sikap dan tindakan yang selalu berupaya mencegah kerusakan pada 
lingkungan alam disekitarmya dan mengembangkan upaya-upaya untuk memperbaiki kerusakan alam yang sudah terjadi. Pelukisan nilai peduli lingkungan dapat dilihat pada kutipan percakapan sebagai berikut.

"Coba sawangen kae Bumi Sukowati kang dadekake beloting Tumenggung Mertalaya yo awit saka kahanan wewangunan sing ora maju. Akeh dalan kang rusak jeglongan sewu mbok menawa kuwi luput anggone ngetung merga yen aku liwat dalanku tumuju marang bumi Sukowati ngredem angkara murka kang dumadi nemu mayuta-yuta jeglongan kang tak temoni. Yen ta kayangene kahanan diterusake apa ora saya rusak."

"Coba lihat itu Bumi Sukowati yang menjadikan curangnya Tumenggung Mertalaya ya karena dari keadaan bangunan yang tidak maju. Banyak jalan yang rusak lubang seribu yang mungkin itu salah ketika menghitung karena ketika saya lewat jalanku menuju ke Bumi Sukowati meredakan angkara murka menjadi berjutajuta lubang yang saya temui. Karena seperti ini keadaannya dibiarkan apa ya tidak semakin rusak."

Berdasarkan kutipan percakapan di atas, terdapat nilai peduli lingkungan yang ditunjukkan oleh Pangeran Mangkubumi. Dalam percakapan tersebut, Pangeran Mangkubumi sangat kecewa terhadap kerusakan lingkungan seperti bangunan tidak maju dan jalan yang berlubang karene ulah Tumenggung Mertalaya. Oleh karena itu, Pangeran Mangkubumi berusaha memperbaiki kerusakan yang dan menjadikan bangunan menjadi lebih maju.

\section{Peduli sosial}

Nilai peduli sosial dapat ditunjukkan melalui sikap dan tindakan yang selalu ingin memberi bantuan pada orang lain dan masyarakat yang membutuhkan. Memberi bantuan dalam hal kebaikan akan menumbuhkan sikap tidak sombong, rendah hati, dan peka terhadap lingkungan. Nilai peduli sosial dilukiskan melalui kutipan percakapan berikut.

"Yen terus kaya mengakne kahanannegara, ora wurung sak Surakarta kang bakal dadi kurban. Mula saka kuwi Jayasentana, cuwa rasaning atiku, gembung rasane penggalihku, ora babagan bebungah kang kudu tak tanpa nanging aku menggalihake nglawan kahanane Praja Surakarta Hadiningrat iki ing tembe mburi."

"Kalau terus seperti ini keadaan negara, tidak lain se-Surakarta yang akan menjadi korban. Oleh karena itu, Jayasentana, kecewa rasanya hatiku, marah rasanya hatiku, bukan hal menyengkan yang harus saya terima tetapi saya miris melihat keadaan Keraton Surakarta Hadiningrat ini di kemudian hari."

Berdasarkan kutipan percakapan tersebut, terdapat nilai peduli sosial yang ditunjukkan oleh Pangeran Mangkubumi. Pangeran Mangkubumi merasa sangat sedih dan kecewa melihat keadaan masyarakat se-Surakarta yang dijajah kompeni. Oleh karena itu, beliau akan berjuang dan berkorbang apapun untuk mengusir penjajah demi masyarakatnya bisa sejahtera.

\section{Tanggung jawab}

Nilai tanggung jawab dilukiskan dengan sikap dan perilaku seseorang untuk melaksanakan tugas dan kewajibannya, yang seharusnya dia lakukan terhadap diri sendiri, masyarakat, lingkungan (alam, sosial, dan budaya), negara dan Tuhan Yang Maha Esa. Tanggung jawab adalah melakukan tugas sepenuh hati, mampu mengontrol diri dan mengatasi stres, akuntabel terhadap pilihan dan keputusan yang diambil. Pelukisan nilai tanggung jawab dapat dilihat pada kutipan percakapan Pangeran Mangkubumi sebagai berikut. "Aku bakal tinggal praja. Yen ta pancen nggonku lunga saka negara Surakarta iki kriwikan dadi grojogan wis tak antebi." 
"Aku akan meninggalkan keraton. Apabila memang benar kepergianku dari negara Surakarta ini menjadi masalah besar sudah sudah saya pertanggungjawabkan."

Berdasarkan kutipan percakapan tersebut, rasa tanggung jawab yang diperlihatkan dalam wayang kulit lakon "Ndaru Ing Bumi Sukowati"adalah tanggung jawab seorang yang berani menerima konsekuensi atas tindakan yang telah dilakukan atau pilihan yang telah dipilihnya. Pangeran Mangkubumi memutuskan meninggalkan keraton karena ingin melawan penjajah dan beliau akan menerima segala konsekuensinya dan mempertanggungjawabkannya.

\section{KESIMPULAN}

Lakon "Ndaru Ing Bumi Sukowati"
bercerita tentang perjuangan Pangeran Mangkubumi melawan penjajah Belanda hingga mendirikan Pemerintahan di Sragen. Ditengah beratnya perjuangan muncul tokoh Patih Pringgalaya yang berkhianat dengan cara licik menjadi antek Belanda. Pangeran Mangkubumi cukup waspada sehingga berbagai persoalan bisa diatasi. Pangeran Mangkubumi adik dari Sunan Paku Buwono II di Mataram sangat membenci Kolonialis Belanda. Apalagi setelah Belanda banyak mengintervensi Mataram sebagai Pemerintah yang berdaulat. Oleh karena itu dengan tekad yang menyala Bangsawam tersebut lolos dari istana dan menyatakan perang dengan Belanda.

Nilai-nilai pendidikan karakter yang terkandung di dalam pertunjukan wayang Cokek lakon "Ndaru Ing Bumi Sukowati" antara lain; jujur, disiplin, kerja keras, kreatif, mandiri, demokratif, rasa ingin tahu, semangat kebangsaan, cinta tanah air, mengahargai prestasi, bersahabat/komunikatif, cinta damai, gemar membaca, peduli lingkungan, peduli sosial, dan tanggung jawab. Berdasarkan temuan nilai-nilai pendidikan karakter yang terkandung di dalam wayang Cokek pada lakon tersebut, cerita ini dapat dijadikan sebuah model dalam membangun pendidikan karakter generasi bangsa baik dalam bidang akademik maupun nonakademik.

\section{DAFTAR PUSTAKA}

Budiasa, I. M. 2014. Memahami NilaiNilai Budaya Tradisi dalam Lakon Seni Pertunjukan Bali: sebagai Wahana Pendidikan Karakter Bangsa. Aksara, 26 (2), 157-167.

Cahya. 2016. Nilai, Makna, dan Simbol dalam Pertunjukan Wayang Golek sebagai Representasi Media Pendidikan Budi Pekerti. Panggung, 26 (2), 117-127.

Herawati, E. N. 2015. Nilai-nilai Karakter yang Terkandung dalam Dolanan Anak pada Festival Dolanan Anak se-DIY 2013. Imaji, 13 (1), 13 - 27.

Megawangi, R. 2004. Pendidikan Karakter, Solusi yang Tepat untuk Membangun Bangsa. Jakarta: Indonesian Heritage Foundation.

Mubah, A. S. Strategi Meningkatkan Daya Tahan Budaya Lokal dalam Menghadapi Arus Globalisasi. Fisip Universitas Airlangga,24 (4), 302-308.

Kemendiknas. 2010. Pengembangan Pendidikan Budaya dan Karakter Bangsa. Jakarta: Kementerian Pendidikan Nasional.

Narwanti, S. 2011. Pendidikan Karakter Pengintegrasian 18 Nilai Pembentukan Karakter dalam Mata Pelajaran. Yogyakarta: Familia (Grup Relasi IntiMedia).

Noviyanti, S. R. \& Sutiyono. 2017. Bentuk, Perubahan Fungsi, dan Nilai-nilai Edukatif pada Musik Tari Japin Tahtul di Amuntai. Imaji, 15 (1), 97 - 112.

Nugraheni, W. 2018. Penanaman Nilainilai Moral melalui Kesenian Reog Kendang terhadap Pelajar di Kabupaten Tulungagung. Imaji, 16 (2), $162-171$.

Retnowati, T. H., Mardapi, M., Prihadi, B. 2017. Dimensi Karakter dalam Penilaian Proses Berkarya Seni Lukis Peserta Didik Sekolah Menengah Kejuruan. Imaji, 15 (2), $229-226$. 
Salu, V. R. 2017. Nilai-nilai Pendidikan Multikulturalisme pada Musik Tradisional Tali Dua di Pulau Batang Dua Kota Ternate Maluku Utara. Imaji, 15 (1), 68 - 79.

Santoso, I. B. 2011. Saripati Ajaran Hidup Dahsyat dari Jagad Wayang. Yogyakarta: Flashbook.
Sarwanto. 2008. Pertunjukan Wayang Kulit Purwadalam Ritual Bersih Desa KajianFungsi dan Makna. Surakarta: ISI Press Surakarta dan CV Cendrawasih.

Sugiyono. 2006. Memahami Penelitian Kualitatif. Bandung: Alfa beta.

Suharyono, B. 2005. Wayang Beber Wonosari. Wonogiri: Bina Citra Pustaka. 